Endocrinol. Japon. 1985, 32 (2), 337-345

\title{
NOTE
}

\section{A Malignant Pheochromocytoma with Ileus, Polyuria and Hypercalcemia : A Case of Recurrence 17 Years after the Initial Operation}

\author{
Tsuneharu BABA, Koji MACHIDA, Isamu ozAKi, \\ TOSHImi OKUSHIMA, SHUYA MURABAYASHI, YOSHIMASA KAMATA*, \\ KENICHI IMAMURA AND KAZUO TAKEBE
}

Third Department of Internal Medicine, *First Department of Pathology, Hirosaki University School of Medicine, Hirosaki 036

\begin{abstract}
A case of malignant pheochromocytoma, with a recurrence 17 years after the initial diagnosis of benign pheochromocytoma, was presented. The autopsy revealed multiple metastases of pheochromocytoma to the bone marrow of the thoracic and lumbar vertebrae. Of particular note is the fact that the patient was associated with paralytic ileus, polyuria and hypercalcemia and that he died of hypercalcemia crisis. Cases like this appear to be very rare.
\end{abstract}

Malignant pheochromocytoma is a rare disease and the prognosis of the disease is usually poor (Palmieri et al., 1961). Decreased motility of the gastrointestinal tract and resultant constipation are uncommon symptoms of pheochromocytoma (Gifford et al., 1965). Moreover, paralytic ileus is a rare complication of the disease (Cruz and Colwell, 1972). Though hypercalcemia may uncommonly be seen in the disease (Miller et al., 1975), pheochromocytoma associated with hypercalcemic crisis has not been reported yet, as far as we know. This paper presents a case of malignant pheochromocytoma who was found to have multiple metastases of the tumor 17 years after the initial diagnosis of benign pheochromocytoma and expired after developing paralytic ileus, polyuria and prominent hypercalcemia.

Received November 9, 1984

\section{Case Report}

A 41-year-old Japanese man was admitted to Hirosaki University Hospital with pain in the left chest and right hip in 1982.

At the age of 15 years, he visited a clinic with palpitation and headache, and high blood pressure was pointed out. In 1965 , at the age of 23 years, his blood pressure was $195 / 130 \mathrm{mmHg}$ and urinary excretion of catecholamines was excessive (norepinephrine $1,047 \mu \mathrm{g} /$ day and epinephrine $124 \mu \mathrm{g} /$ day). Under a diagnosis of pheochromocytoma, abdominal surgery was done and a tumor, which abutted on the right adrenal gland and weighed $43 \mathrm{~g}$, was excised. The histological examination revealed that the tumor was pheochromocytoma. Since no metastasis of the tumor was found, it was diagnosed as benign pheochromocytoma. During the 5 years 
following the operation his blood pressure remained normal. However, he did not come to hospital thereafter, and neither his blood pressure nor urinary excretion of catecholamine was measured till 1982.

He was first admitted to the department of orthopedics of our hospital on September 7, 1982. Bone scintigrams revealed concentrations of $99 \mathrm{mTc}$ and ${ }^{201} \mathrm{Tl}$ at the sites of the right 5 th rib, the left 7 th rib and the right ischium. The plasma norepinephrine concentration was $12.0 \mathrm{ng} / \mathrm{ml}$ and epinephrine was $0.04 \mathrm{ng} / \mathrm{ml}$. Urinary excretion of norepinephrine was more than $2,000 \mu \mathrm{g} /$ day and epinephrine was $8.3 \mu \mathrm{g} /$ day. Under a diagnosis of metastatic pheochromocytoma, excision operation of the ribs and the ischium was done on October 18 . Histological examination revealed that the tumors were pheochromocytoma.

When he was transferred to our ward on February 17, 1983, the blood pressure averaged $200 / 130 \mathrm{mmHg}$ in the supine position. The heart rate was 120 beats per minute. A grade $2 / 6$ systolic murmur was heard in the third left intercostal space, but

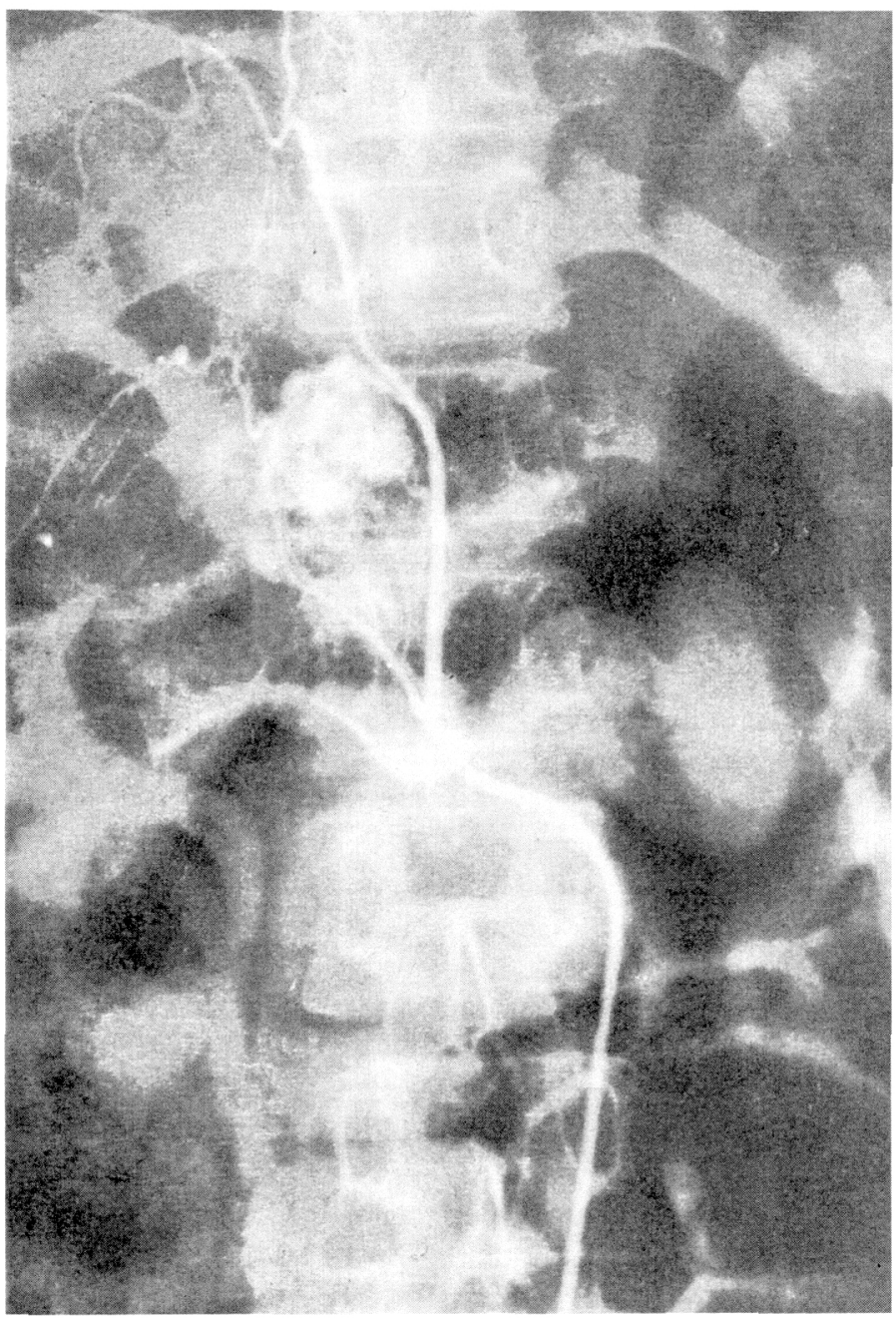

Fig. 1. Angiogram of inferior adrenal artery showing the hypervascular mass. 
the heart size and rhythm were normal. He was $167 \mathrm{~cm}$ tall, weighed $62 \mathrm{~kg}$, was pale and restless and showed excessive sweating. The plasma norepinephrine concentration was $14.9 \mathrm{ng} / \mathrm{ml}$ and epinephrine $0.04 \mathrm{ng} / \mathrm{ml}$. Basal supine plasma renin activity (PRA) was elevated to $6.8 \mathrm{ng} / \mathrm{ml} / \mathrm{h}$. Findings from the other hormonal studies, ie, $T_{3}, T_{4}$, somatostatin, methionine- and leucine-enkepharine were all within the normal range except for the elevated level of plasma gastrin $(240 \mathrm{pg} / \mathrm{ml})$.

Computed tomography revealed a mass posterior to the inferior vena cava at the level of the upper pole of the right kidney. The mass was hypervascular as seen in Fig. 1. Blood was sampled serially from the vena cava in the locations shown in Fig. 2. A markedly high level of norepinephrine concentration was demonstrated in the superior vena cava just above the level of the right atrium and in the inferior vena cava just below the level of the renal veins. An adrenal scintigram revealed a normal concentration of ${ }^{75} \mathrm{Se}$ at the site of the left adrenal gland. However, the concentration was reduced or almost eliminated at the site of the right adrenal gland.

He was treated with $5 \mathrm{mg}$ of prazosin hydrochloride and $60 \mathrm{mg}$ of propranolol hydrochloride. The systolic blood pressure was mostly held under $180 \mathrm{mmHg}$, but the pulse rate remained rapid at over 100 per minute. Oral administration of nifedipine $(10 \mathrm{mg})$ was effective when the blood pressure spontaneously rose to over $250 \mathrm{~mm} \mathrm{Hg}$.

Loss of appetite, nausea, hypoactive bowel sounds and progressive abdominal distension developed shortly after he had been transferred. Severe constipation persisted and paralytic ileus was then diagnosed on March 4, 1983, and was relieved by 1 to 2 liters of warm water enema with soap every day. A contrast medium, which had been given for the stomach examination on February 21, was still observed in the cecum area in the plain roentgenogram of the abdomen on March 14. Besides the severe constipation, an increase in the volume of urine was observed. His daily urine output was 2 to 3 liters during the first few weeks in our ward, but increased gradually until it exceeded .5 liters per day by March 2 . Blood urea nitrogen and serum creatinine were normal. The mean specific gravity of the urine was 1,012 in February and 1,008 in March and the plasma antidiuretic hormone $(\mathrm{ADH})$ level was within the normal range (3.2 $\mathrm{pg} / \mathrm{ml})$.

Serum calcium, which had continued to increase since his transfer, was elevated to $14.0 \mathrm{mg} / \mathrm{dl}$ by March 12 . Serum inorganic phosphate was $2.9 \mathrm{mg} / \mathrm{dl}$. The sernm calcitonin level was $120 \mathrm{pg} / \mathrm{ml}$ (normal range: below $300 \mathrm{pg} / \mathrm{ml}$ ) and PTH was $0.2 \mathrm{ng} / \mathrm{ml}$ (normal range: below $0.5 \mathrm{ng} / \mathrm{ml}$ ). Ionized calcium was $3.27 \mathrm{mEq} / \mathrm{L}$ (normal range : 2.10 to $2.35 \mathrm{mEq} / \mathrm{L}$ ). Urinary excretion of calcium was 800 to $1,170 \mathrm{mg} /$ day. Urinary excretions of prostaglandin $E_{1}$ and $E_{2}$ were both within the normal range. Drip

\section{VENOUS SAMPLING}

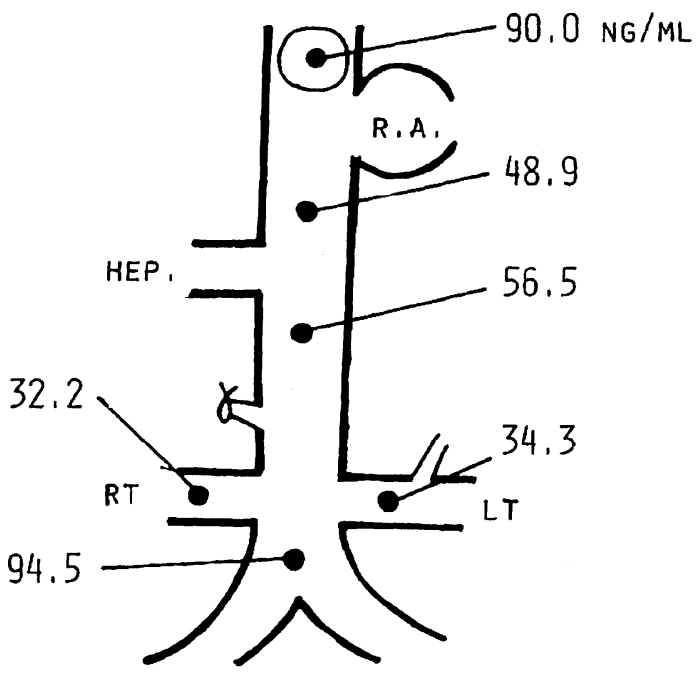

Fig. 2. Norepinephrine concentrations of blood sampled serially from" the vena cava. 
infusion of saline, intramuscular injection of calcitonin and oral administration of predonin every day were started on March 14 to lower the high calcium level. Serum calcium was then lowered to $12.0 \mathrm{mg} / \mathrm{dl}$ on April 6 and $11.2 \mathrm{mg} / \mathrm{dl}$ on May 4. However, serum calcium again increased gradually thereafter in spite of the same treatment for hypercalcemia. And it was elevated to $16.6 \mathrm{mg} / \mathrm{dl}$ on May 31 . Shivering, vomiting, drowsiness, paralysis of extremities, cyanosis and arrythmia developed. Drip infusion of mithramycin (1.25 $\mathrm{mg}$ ) lowered the serum calcium level to $11.0 \mathrm{mg} / \mathrm{dl}$ on June 2 . However, his general condition remained unchanged and he died suddenly in the morning of June 3 .
April 1985

\section{Pathology}

At autopsy a light brown thumb's headsized tumor with focal hemarrhage and necrosis was found in the location between the inferior vena cava and the upper pole of the right kidney. The tumor had 2 modules; one was a little finger's headsized and the other was cherry-sized. The latter nodule projected into the lumen of the vena cava (Fig. 3). The histologic pattern was typical of pheochromocytoma (Fig. 4). Remnants of the adrenal gland was not seen. An analysis for catecholamine revealed $558,000 \mu \mathrm{g}$ of norepinephrine per gram of the tumor tissue. However, epinephrine was below the detectable level. Norepinephrine and epinephrine levels in the left adrenal gland were $34,500 \mu \mathrm{g}$ and 110,000 $\mu \mathrm{g}$ per gram of the tissue. The bone marrow of the thoracic and lumber vertebrae was replaced by brown tumors (Fig. 5), which

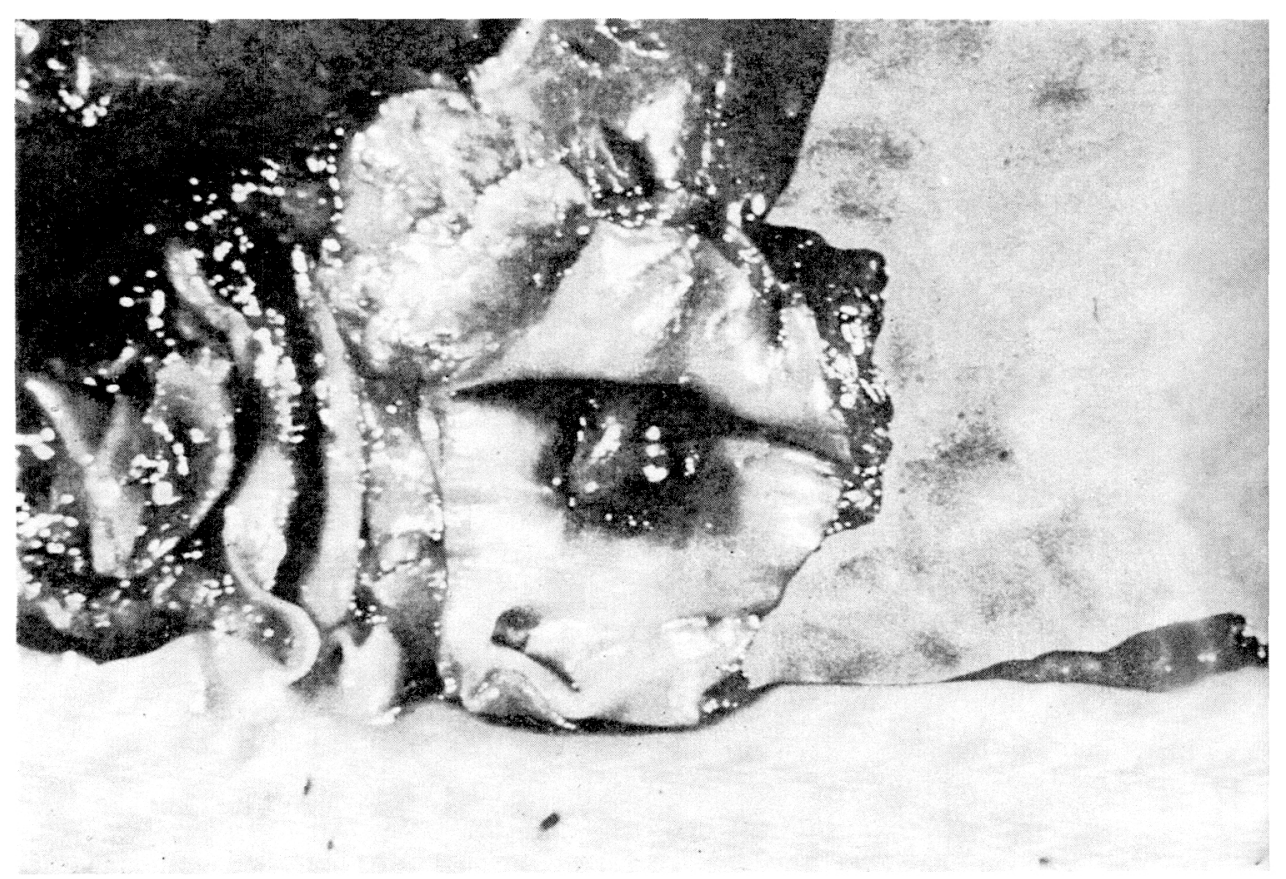

Fig. 3. Pheochromocytoma projected into the lumen of the vena cava. 


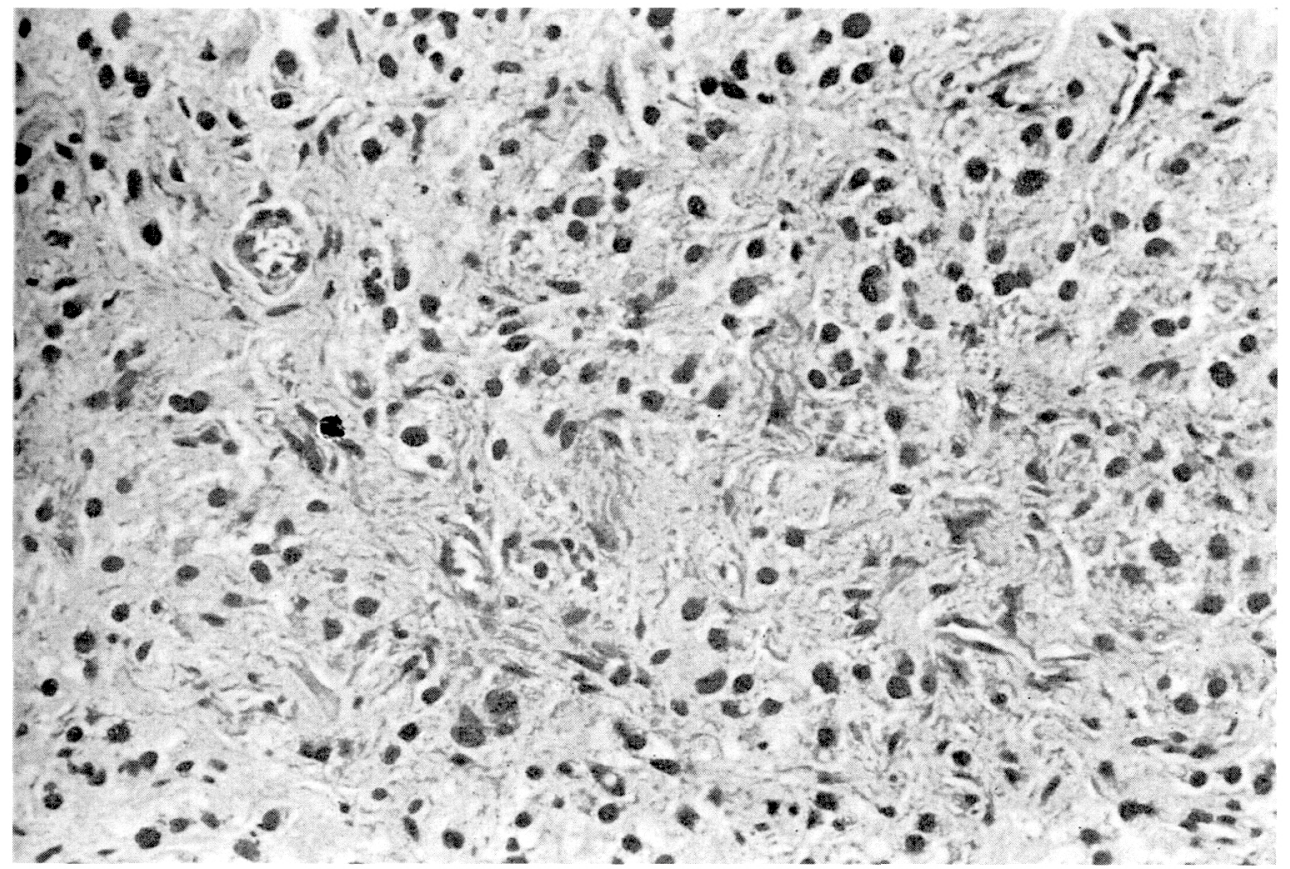

Fig. 4. Microphotograph of malignant pheochromocytoma arising from the area of the right adrenal gland, showing large polygonal cells. $(\mathrm{H} \& \mathrm{E} \times 100)$

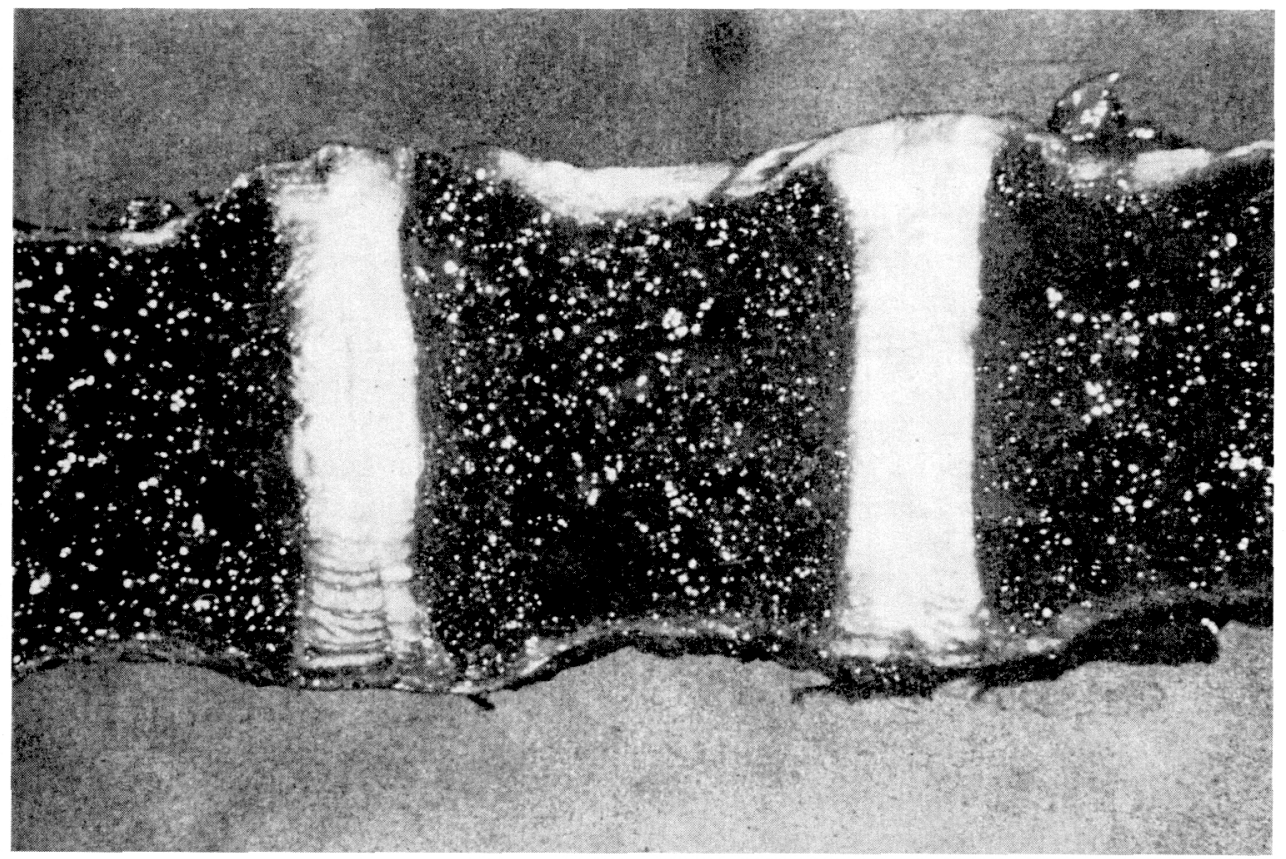

Fig. 5. The bone marrow of the lumbar vertebrae was replaced by metastatic pheochromocytoma. 
tissue contained $107,000 \mu \mathrm{g}$ per gram of norepinephrine. The thyroid gland and 3 parathyroid glands found were normal. The colon was filled with a large amount of impacted stool and distended with a thinned-out wall. It was accompanied with congestion, focal bleeding and necrosis. The nerve plexuses of Auerbach in the colon wall were normal. No occlusion was found in the superior and inferior mesenteric arteries. The histological examination of the kidneys revealed slight hyalinization of glomerulus and prominent metastatic calcification in the epithelial cells of proximal tubules, loops of Henle and distal tubules.

\section{Comments}

The present case of malignant pheochromocytoma is unique because of his long survival and of extremely rare complications.

The prognosis of malignant pheochromocytoma is usually poor (Palmieri et al., 1961; James et al., 1972). The 5-year survival rate subsequent to treatment was $96 \%$ for benign tumors and $44 \%$ for malignant tumors (Remine et al., 1974). The mean interval between the primary tumor and the recurrence was from 5.6 (Remine et al., 1974) to 8 years (Mahoney and Harrison, 1977). Meanwhile, some cases with a long survival were also reported (Scharf et al., 1973; Mahoney and Harrison, 1977). Remine et al. (1974) recorded 4 patients who were alive with the disease at $5,20,20$ and 21 years. In Japan 69 cases of malignant pheochromocytoma had been reported by the end of December in 1983 (Miura and Ishizuka, 1984). And as far as we know, the case reported here survived longer than any other recorded in Japan. One cannot be certain whether a tumor is benign or malignant even after removal of the tumor (Priestley et al., 1963), unless a metastasis is found. In that sense, Mahoney and Harrison (1977) recommended all patients with pheochromocytoma to have a detailed followup for 15 years. In our patient the recurrence developed 16 years after the initial operation. Therefore, we recommend that close follow-ups of the patients should be done every 6 months for more than 15 years. We think that the follow-up study should at least include measurements of blood pressure, pulse rate and urinary excretion of catecolamines.

The multiple bone metastases are most likely a cause of the hypercalcemia in our patient. The metastases in the vertebral column may explain the dispersed peaks of norepinephrine levels obtained at the time of the vena caval blood sampling. Hypercalcemia associated with pheochromocytoma is mostly attributable to concomitant primary hyperparathyroidism (MEN type 2) (Miller et al., 1975). However, in our patient the serum calcitonin level was not elevated and the pathological examination revealed neither medullary thyroid carcinoma nor parathyroid hyperplasia. Moreover, a normal level of PTH also can rule out the possibility that an increased level of catecholamine might have stimulated PTH release from the parathyroid gland (Swinton et al., 1972; Kukureja et al., 1973). Still there is the question whether the bone metastases were the only cause of the hypercalcemia and hypercalcemic crises. In previous reports malignant pheochromocytoma with bone metastases did not always accompany hypercalcemia (Herrera et al., 1980; Scott et al., 1982) and the correlation between the extent of bony lesions and hypercalcemia was poor. As to this, Kimura et al. (1982) suggested that the velocity of bone destruction was an important factor in developing hypercalcemia in malignant tumors in general. It is possible that the tumor produced other osteolytic substances such as prostaglandins (Finlayson and Casey, 1975; Plean et al., 1976), or some PTH like substance which cannot be detected by the present radioimmunoassay. Mithramycin was effective in reducing the 
serum calcium concentration in this case. The level of serum calcium was decreased from $16.6 \mathrm{mg} / \mathrm{dl}$ to $11.0 \mathrm{mg} / \mathrm{dl}$ in 2 days. Our experience supported the previous observation that this cytotoxic substance was useful in the treatment of hypercalcemia which had been resistant to treatment with combinations of saline, calcitonin and glucocorticoids (Kimura et al., 1982).

Decreased gastrointestinal motility and resultant constipation are uncommon symptoms of pheochromocytoma (Gifford et al., 1964). In a series of 68 cases constipation was recorded in only $8 \%$ (Hume, 1960). Paralytic ileus is, moreover, a rare complication of the disease. A review of the English literature revealed only 8 previously described cases (Cruz and Colwell, 1972). In Japan only 2 cases with paralytic ileus have been recorded in literature (Okuno et al., 1983; Ishizuka et al., 1983). Decreased motility of the gastrointestinal tract can be predicted from the phamacological effects of catecholamines, which appeared to be mediated through alph $_{2}$ - and beta ${ }_{2}$-adrenergic receptors (Mayer, 1980). Besides the action of catecholamines, hypercalcemia might have played a role in developing the obstinate constipation. It is known that ionized calcium is essential in neuromuscular transmission. Therefore, the loss of smooth muscle tone and decreased activity of the autonomous nerve due to the hypercalcemia, as well as the action of catecholamines, might have developed the paralytic ileus. The absence of clinical symptoms, such as severe abdominal pain and shock, and the pathological findings can rule out the possibility that an occlusion of the major vessels in the mesentery might have caused the paralytic ileus.

Polyuria is another uncommon symptom of pheochromocytoma (Graham, 1951 ; Stackpole et al., 1963). Norepinephrine is known to increase the renal water excretion (Schrier et al., 1975). This action is considered to be mediated by suppression of $\mathrm{ADH}$ release
(Schrier et al., 1975). In our case the ADH level was not elevated in spite of the marked polyuria and of possibly decreased total blood volume (Sjoerdsma et al., 1966). On the other hand, hypercalcemia is known to inhibit the effect of ADH on water flow across the renal tubules (Epstein, 1968). The metastatic calcification in the tubular epithelial cells might indicate the disturbance of tubular function (Cotran, 1981). The urine volume appeared to have increased rather in parallel with the rise in the serum calcium level. Therefore, the marked polyuria observed in this case seemed to be attributable to the effects of both hypercalcemia and increased secretion of catecholamine.

An elevated level of gastrin was observed in our patient. Hypergastrinemia has been reported in patients with pheochromocytoma (Hayes et al., 1972; Sagara et al., 1981; Tatsuta et al., 1983). Intravenous infusion of epinephrine increased gastrin secretion (Christensen and Stadil, 1976; Hayes et al., 1978) and this response was prevented by the administration of propranolol (Hayes et al., 1978). Intravenous infusion of neither norepinephrine (Christensen and Stadil, 1976) nor phenylephrine (Hayes et al., 1978) stimulated gastrin secretion. Therefore, stimulation of gastrin release by catecholamine was considered to be a beta-adrenergic effect (Hayes et al., 1978). Tatsuta et al. (1983) observed that the serum gastrin level was elevated in pheochromocytoma with a high serum epinephrine level, but not in those with a normal epinephrine level. In our case, the plasma epinephrine level was within the normal range although the norepinephrine level was high. Norepinephrine is known to have the effects of alpha $_{1^{-}}$, alpha $2_{2}$ and also beta ${ }_{1}$-adrenergic agonist (Lee, 1981). Therefore, a very high level of norepinephrine might have stimulated gastrin secretion by its beta-adrenergic action in our patient. 


\section{Acknowledgements}

The authors are grateful to Mitsubishi Yuka Laboratory of Medical Science (Tokyo, Japan) for measurements of tissue catecholamine contents.

\section{References}

Christensen, K. C. and F. Stadil (1976). Effect of epinephrine and norepinephrine on gastrin release and gastric secretion of acid in man. Scand. J. Gastroenterol. 37, 87-92.

Cotran, R. S. (1981). Tubulointcrstitial diseases. In: The kidney (B. M. Brenner and F. C. Rector ed.), W. B. Saunders Co., Philadelphia. pp. 1633-1667.

Cruz, S. R. and J. A. Colwell (1972). Pheochromocytoma and ileus. J.A.M.A. 219, 10501051.

Epstein, F. H. (1968). Calcium and the kidney. Am. J. Med. 45, 700-714.

Finlayson, J. F. and J.H. Casey (1975). Hypercalcemia and multiple pheochromocytomas. Ann. Int. Med. 82, 810-811.

Gifford, R. W., F. T. Kvale, F. T. Maher, G. M. Roth and J. T. Priestley (1964). Clinical features, diagnosis and treatment of pheochromocytoma : a review of 76 cases. Mayo Clinic Proceedings 39, 281-302.

Graham, J. B. (1951). Collective review: Pheochromocytoma and hypertension (an analysis of 207 cases). Internal. Abstr. Surg. 92, 105121.

Hayes, J. R., J. Ardill, T. L. Kennedy and R. G. Shanks (1972). Stimulation of gastrin release by catecholamines. Lancet 1, 819-821.

Hayes, J. R., J. Ardill, R. G. Shanks and K. D. Buchanan (1978). Effect of catecholamines on gastrin release. Metabolism 27, 385-391.

Herrera, L. O., Z. M. Hossain, H. S. Rafal, R. W. Frelick, P. F. Ashley and G. E. Lopez (1980). Malignant pheochromocytoma (paraganglioma) of the organ of Zuckerkandl: a study of two cases. J. Surg. Oncol. 14, 133145.

Hume, D. M. (1960). Pheochromocytoma in the adult and in the child. Am. J. Surg. 99, 458-496.

Ishizuka, Y., Y. Miura, M. Adachi, H. Seino,
M. Adachi, S. Kimura, K. Yoshinaga, $H$. Ohuchi, K. Iwai, H. Sasano, N. Kimura and S. Morinaga (1983). A malignant pheochromocytoma observed for 14 years with extensive bone metastases. Igaku no Ayumi 127, 213226 (In Japanese).

James, R. E., H. L. Baker and P. W. Scanlon (1972). The roentgenologic aspects of metastatic pheochromocytoma. Amer. J. Roentgen. 115, 783-793.

Kimura, S., T. Yamada, I. Adachi, M. Tanaka, K. Yamaguchi and K. Abe (1982). Two cases of malignancy-associated hypercalcemia treated with mithramycin. Jpn. J. Clin. Oncol. 12, 277-284.

Kukureja, S. C., G. K. Hargis, I. M. Rosenthal and G. A. Williams (1973). Pheochromocytoma causing excessive parathyroid hormone production and hypercalcemia. Ann. Int. Med. 79, 838-840.

Lees, G. M. (1981). A hitch-hiker's guide to the galaxy of adrenoceptors. Brit. Med. J. 283, 173-178.

Mahoney, E. M. and J. H. Harrison (1977). Malignant pheochromocytoma (clinical course and treatment). J. Urol. 118, 225-229.

Mayer, S. E. (1980). Neurohumoral transmission and the autonomic nervous system. In: The pharmacological bases of therapeutics. (L. S. Goodman and A. Gilman ed.), Macmillan Pub. Co., New York. pp. 56-90.

Miller, S. S., G. W. Sizemore, S. G. Sheps and G. M. Tyce (1975). Parathyroid function in patients with pheochromocytoma. Ann. Intern. Med. 82, 372-375.

Miura, Y. and Y. Ishizuka (1984). Catecolamine producing tumors: Epidemiology and pathology of malignant pheochromocytoma. Annual Report of the Ministry of Health and Walfare "Disorders of adrenal hormoness" Research Committee 1983, Japan. 250-257 (In Japanese).

Okuno, T., M. Nishino, H. Kageyama, R. Nakamura, T. Ohguro, T. Saruta and K. Murai (1981). A case of malignant pheochromocytoma. Horumon to Rinsho 29 (Case Presentation), 296-299 (In Japanese).

Palmieri, B., D. Ikkos and R. Luft (1961). Malignant pheochromocytoma. Acta Endocrinol. 36, 549-560.

Plean, F. F., F. Boemer and C. V. Y. Strihou (1976). Hypercalcemic pheochromocytoma. Brit. Med. J. 2, 734.

Preistly, J. T., W. F. Kvale and R. W. Gifford 
(1963). Pheochromocytoma. Clinical aspects and surgical treatment. Arch. Surg. 86, 778790.

Remine, W. H., G. C. Chong, J. A. V. Heerden, S. G. Sheps and E. G. Harrison (1974). Current management of pheochromocytoma. Ann. Surg. 179, 740-748.

Sagara, K., S. Oishi, T. Umeda and T. Sato (1981). Serum gastrin levels in patients with pheochromocytoma. Jap. J. Clin. Oncol. 11, 363-366.

Scharf, Y., A. M. Nahir, O.S. Better, A. Koten, Y. B. Arieh and B. Gellei (1973). Prolonged survival in malignant pheochromocytoma of the organ of Zuckerkandl with pharmacological treatment. Cancer 31, 746-750.

Schrier, R. W., J. A. Harbottle and K. M. McDonald (1975). Catecholamine and renal water excretion. Nephron 15, 186-196.
Scott, H. W., V. Reynolds, N. Green, D. Page, J. A. Oates and D. Robertson (1982). Clinical experience with malignant pheochromocytoma. Surg. Gynecol. Obstet. 154, S01-S08.

Sjoerdsma, A., K. Engelman, T. A. Waldmann, L. H. Cooperman and W. G. Hammond (1963). Pheochromocytoma (current concepts of diagnosis and treatment. Anm. Intern. Med. 65, 1302-1326.

Stackpole, R. H., M. M. Melicow and A. C. Uson (1963). Pheochromocytoma in children. J. Pediat. 63, 315-330.

Swinton, N. W., E. P. Clerkin and L. D. Flint (1972). Hypercalcemia and familial pheochromocytoma. Alln. Int. Med. 76, 455-457.

Tatsuta, M., M. Baba and T. Itoh (1983). Increased gastrin secretion in patients with pheochromocytoma. Gastroenterology 84, 920923. 